\title{
Организация взаимодействия
} промышленных потребителей с поставщиками в рамках закупочных процедур: проблемы и решения на микроуровне

\begin{abstract}
(C) 2017 г. В.И. Плещенко*
В статье рассмотрены различные подходы к организации закупок продукции для производственных нужд, проанализированы их преимущества и недостатки. Показано, что несмотря на расширившуюся в западных странах практику закупки товаров у единственного источника, для современных промышленных предприятий в России в настоящее время более предпочтительными являются подходы, предусматривающие альтернативный выбор поставщиков, соревновательность различных предложений участников закупочных процедур. При анализе проблемы на микроуровне отмечена особая важность этапа подготовки к проведению закупки, на котором необходимо оценить обоснованность трансакционных издержек участников, их адекватность при сопоставлении с параметрами планируемой сделки и текущей рыночной ситуацией. Поскольку современные взаимоотношения сторон не должны соответствовать игре «с нулевой суммой», то для обеспечения результативности проводимых процедур покупателю следует стремиться к нахождению точки равновесия с привлекаемыми им участниками. На взгляд автора, популярные сегодня регламентированные торги эффективны преимущественно на коротких дистанциях. Расширение круга участников процедур способно лишь на некоторое время повысить их результативность, однако при этом организатор сталкивается с новыми для себя рисками и проблемами. Поэтому в перспективе более рациональным вариантом для промышленной компании представляется структурирование отношений с поставщиками с переходом на использование модели рыночных закупок материалов производственного назначения, в большей степени подходящей для развития партнерских отношений. При этом промышленному потребителю необходимо осуществлять сбалансированное управление массивом контрагентов, формируя на их базе конкурентную среду лояльных поставщиков.
\end{abstract}

Ключевые слова: закупочная процедура, единственный источник, конкурентные закупки, трансакционные издержки, цена лояльности, долгосрочное сотрудничество

Основная задача процесса закупок на промышленном предприятии - своевременное обеспечение производственного процесса необходимыми материально-техническими ресурсами по приемлемым, экономически обоснованным ценам. Эволюция закупочной деятельности такова, что из технической функции снабжения, ориентированной на выполнение заказа, закупки трансформировались в сложный процесс межфункционального взаимодействия, оказывающий существенное воздействие на успех предпринимательской деятельности [1, С. 22; 2 , С. $10 ; 3$, С. $14 ; 4$, С. 122, 5, С. 164]. Особое значение закупочной деятельности для обеспечения конкурентоспособности промышленной компании определяется тем, что от организации работы службы

* Канд. экон. наук, начальник управления, v_pl@mail.ru АО «Гознак», 197046, Санкт-Петербург, Петропавловская крепость, д. 3, литера «В». снабжения зависит не только стабильное и ритмичное функционирование производства, но и себестоимость готовой продукции. Авторитетная консалтинговая фирма KPMG приводит данные, что доля затрат на закупки в промышленности России колеблется в пределах от 26 до 65 \% от величины выручки компаний [6]. По другим данным, возможность оптимизации финансовых затрат промышленных предприятий на 50 \% зависит от состояния вопроса сотрудничества с поставщиками [7]. Следовательно, решение актуальной задачи повышения эффективности бизнеса, снижения текущих издержек во многом определяется избранной компанией стратегии взаимодействия с поставщиками.

На первый взгляд, глобализация, трансграничная торговля и бурное развитие электронной коммерции должны способствовать привлечению все большего числа участников к процедурам закупок, расширению круга контрагентов [8, 9], однако многие исследователи отмечают, что в современном 
мире (особенно у крупных потребителей за рубежом) сформировалась обратная тенденция. Как ни странно это может показаться, но данная рыночная тактика применяется ими в целях экономии, поскольку меньшее число поставщиков означает повышение объема закупки, приходящегося в среднем на одного контрагента, стимулируя снижать цены, и, кроме того, при таком подходе уменьшаются трансакционные издержки [10, С. 33-34]. Все это означает, что на микроуровне потенциальная экономия от снижения закупочных цен за счет использования нескольких источников удовлетворения потребности во многих случая оказывается меньше, чем суммарные затраты, вытекающие из необходимости обслуживания новых отношений. К примеру, в случае разделения объема поставки на несколько лотов между конкурирующими продавцами произойдет неизбежное удорожание поставляемых партий товара как минимум за счет логистических затрат. Также на ситуацию оказывает влияние фактор стоимости (цены) замещения ресурса или поставщика, а именно: дополнительных затрат предприятия на переподготовку персонала, закупку оборудования, оплату технической помощи и др. [11, С. 9; 12]. Поэтому американский ученый Ф. Уэбстер отметил, что в условиях внедрения многими промышленными компаниями системы обеспечения производства ресурсами по принципу «точно в срок» и ускоренной обработки заказов все большее распространение в мире получает практика закупки товара у единственного источника [13, С. 37].

В то же время для России актуальной рекомендацией для промышленных предприятий остается привлечение большего количества поставщиков с целью иметь прозрачный механизм ценообразования и повысить дисциплину среди контрагентов [14, С. 47], а также снизить риски сбоя поставок от единственного источника [15, С. 16]. Только затем, на основании полученного опыта взаимодействия, можно будет задаться вопросом о структуризации поставщиков и их перспективности (с точки зрения долгосрочного взаимодействия).

Сегодня в России даже долгосрочные партнерские отношения взаимосвязанных субъектов рынка не являются гарантией отсутствия крупных проблем со снабжением. В частности, довольно показательной стала ситуация во взаимоотношениях ведущих российских промышленных корпораций: ММК и «Русал», связанная с нежеланием сторон договориться об условиях поставки важного сырья, необходимого для производства алюминия, - каменноугольного пека [16]. Следствием стала жалоба ММК в ФАС России на «Русал», который, по мнению заявителя, навязывал комбинату невыгодные условия договора, злоупотребляя доминирующим положением единственного потребителя в России. В итоге предупреждение от ФАС получили обе компании, поскольку выяснилось, что ММК также нарушал антимонопольное законодательство, навязывая покупателю свою цену и приостанавливая у себя производство пека, из-за чего «Русал» был вынужден возобновить закупку данного материала по импорту во избежание остановки алюминиевых заводов ${ }^{1}$.

В настоящее время весьма актуальными для отечественных промышленных потребителей остаются научно-практические исследования. в области организации конкурентных закупок, привлечения к процедурам новых поставщиков, повышения стабильности и эффективности материально-технического снабжения производства.

В то же время наличие альтернативных источников удовлетворения возникающих производственных потребностей означает для покупателя необходимость более тщательного планирования процесса закупок, оптимального распределения поставок между несколькими контрагентами, поддержания заинтересованности участников проводимых процедур к сотрудничеству, а также формирования конкурентной среды в рамках массива поставщиков. Следовательно, вопрос информационного взаимодействия с внешней средой в лице потенциальных участников закупки является одним из ключевых при организации конкурентных процедур отбора, поскольку именно активность поставщиков позволяет потребителю получать рыночное предложение необходимых ему материально-технических ресурсов на достаточном уровне [18, С. 32]. Поэтому предприятию будет недостаточно лишь проинформировать целевые компании о планируемых закупках, необходимо еще обеспечить заинтересованность последних для участия в процедурах. Этому может способствовать практическое применение принципов конкурентных закупок, основанных на обеспечении открытости и прозрачности процедур, конкурентности, равенства и справедливости для всех участников, эффективности и обоснованности закупок [19, С. 11-12].

При этом традиционно считается, что конкурентные закупки (в особенности регламентированные торги) предполагают доминирование покупателя над поставщиками, навязывание им своей воли. Автор предлагает провести анализ на микроуровне с целью определения истинности данной предпосылки.

Во многих случаях, в рамках проведения торгов и ведения переговорного процесса пожелания, высказываемые сторонами в части параметров сделки и условий сотрудничества, могут быть диаметрально противоположными. Также вполне возможно, что сегодняшнее согласие одной стороны с каким-либо требованием вызовет для него дополнительные затраты и риски в будущем. Соответственно, увеличиваются трансакционные

${ }^{1}$ Отметим, что в последнее время все чаще такие органы, как ФАС, выступают в роли медиатора, способствуя досудебному разрешению споров хозяйствующих субъектов. К примеру, в январе 2017 года с помощью ФАС было достигнуто соглашение между ПАО «НК Роснефть» и АО «Саянскхимпласт», устанавливающее формулу цены на поставляемое сырье - этилен [17]. Автор считает данную тенденцию позитивной. 
издержки контрагента и цена товара, либо поставщик идет на отказ от участия в процедуре или заключения договора.

Продемонстрируем данную ситуацию графически, отложив по оси абсцисс сумму сделки, а по оси ординат - ожидаемые трансакционные издержки, то есть затраты, потери, а также риски, которые придётся понести участнику на этапе отбора (и, в случае победы, при реализации договора). Очевидно, указанные издержки находятся в зависимости от того набора требований (и степени формализации), которые были заложены организатором в условия отборочной процедуры. Предприятие-покупатель, формируя данные требования, a priori исходит из необходимости максимальной защиты своих интересов (отметим, что, чем важнее для него эта сделка, тем больше будет желание снизить риски). Одновременно, следует учитывать, что чем ниже будет сумма предполагаемого контракта, тем меньше затрат на его обслуживание будет готов понести участник закупки и тем слабее станет его готовность следовать условиям процедуры (выполнять процедурные формальности, раскрывать информацию о своей фирме и др.).

Допустим, что зависимость является линейной. В таком случае функция в общем виде может быть представлена уравнением.

$$
\mathrm{TC}=k V+p,
$$

где $k$ - угловой коэффициент; ТС - величина трансакционных издержек, руб.; $V$ - объем сделки, руб.; $p$ - плата за доступ к информации о сделке, руб.

В рассматриваемом случае коэффициент $k$ является величиной, зависящей от сложности условий процедуры, и позволяющей оценить, на какой процент от предполагаемой суммы сделки должна увеличиться цена ресурса Величина $p$ определяет затраты, которые должен понести участник для обладания данными о параметрах проводимой процедуры. Это может быть подписка на информационную рассылку или специализированное издание, плата за регистрацию на электронной торговой площадке. Также в определенных случаях данная величина может включать стоимость выкупа комплекта закупочной документации либо затраты на подписание с организатором соглашения о конфиденциальности (о неразглашении).

Воспользовавшись вышеуказанной функцией, изобразим условные прямые $S$ и $C$, которые будут означать возможные сценарии проведения закупки для поставщика и потребителя соответственно (рис. 1).

Рассматривая первый вариант, можно констатировать тот факт, что потребитель предполагает большие затраты со стороны поставщика-участника процедуры, чем тот готов понести. Также и поставщик не готов взять на себя определенные обязательства. Поскольку обе стороны склонны действовать по принципу игры «с нулевой суммой», то линии $C$ и $S$ не пересекаются и велика вероятность завершения такой закупки без результата, поскольку потенциаль-
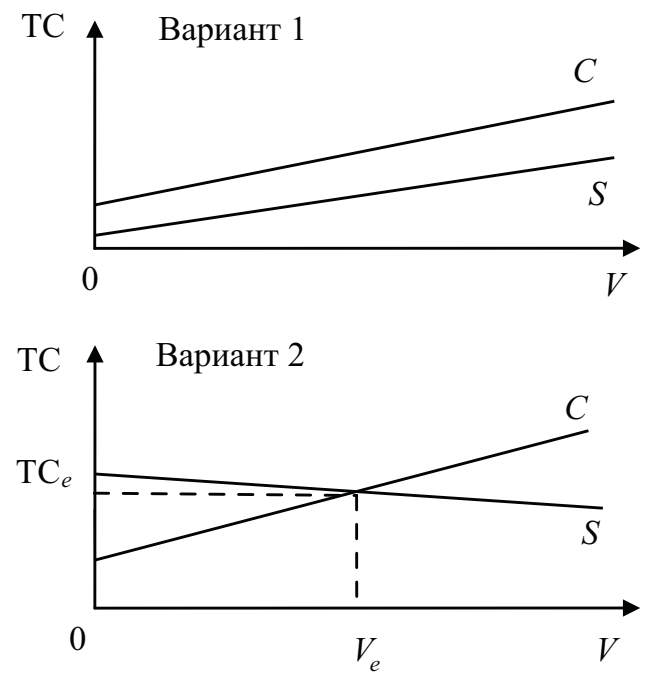

Рис. 1. Различные варианты процедуры закупки

[Various options of a procurement procedure]

ные участники не захотят предоставить свои оферты на заданных условиях. На наш взгляд, такой подход не может считаться оптимальным.

Согласно же второму (компромиссному) варианту условный участник согласен понести на начальном этапе даже большие затраты, чем предложил ему организатор, при условии того, что в будущем они снизятся. Линии $C$ и $S$ пересеклись в точке $\left(\mathrm{TC}_{e}, V_{e}\right)$, которая стала точкой равновесия. Следовательно, оптимизируя параметры процедур отбора, настраивая их в зависимости от конъюнктуры рынка определенного ресурса и других значимых факторов, покупатель может осуществлять сбалансированное управление массивом своих поставщиков.

В этой связи следует отметить, что при осуществлении конкурентных закупок предприятие постепенно набирает определенный массив постоянных участников по определенным видам номенклатуры, в число которых входят и традиционные контрагенты. Модель долгосрочного сотрудничества основывается на следующем допущении: потребитель обеспечивает группе поставщиков доступ к каналу сбыта, но при этом настаивает на соблюдении ими «правил игры». Принятие контрагентами требований покупателя (фактически их лояльность потребителю) означает, в свою очередь, готовность нести определенные издержки и риски. Можно сказать, что в результате на микроуровне возникает особая стоимостная категория - «цена лояльности», которую, как предполагается, оплатит потребитель. Попробуем проанализировать, насколько справедливо данное утверждение.

Как известно, цена любого товара складывается из себестоимости и ожидаемой прибыли предпринимателя. Принимая участие в закупочной процедуре, поставщик несет определенные затраты, соответственно, цена лояльности в предельном случае равняется суммарным трансакционным издержкам продавца. Следовательно, как мы уже показали выше, цена лояльности будет являться некой функциональ- 


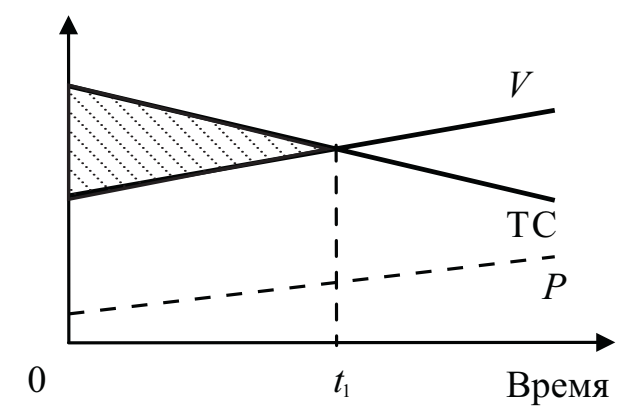

Рис. 2. Соотношение выручки, издержек и прибыли поставщика

[Ratio of revenue, expenses and profit of the supplier]

Примичание: ТС - трансакционные издержки; $V$ - объем продаж; $P$ - прибыль.

ной зависимостью, детерминированной степенью сложности отборочного мероприятия. Также очквидно, что продавец будет стремиться учесть указанные затраты в цене предлагаемого продукта. В то же время, если на товарном рынке существует развитая конкурентная среда, а организаторы закупки противодействуют сговору поставщиков, то эти затраты в той или иной степени будут относиться участниками закупки на свой счет. Продавец будет стремиться учесть указанные затраты в цене предлагаемого продукта (в зависимости от того, на какое снижение показателя рентабельности продаж согласен поставщик при заданных параметрах ожидаемой сделки).

Более того, когда сотрудничество сторон приобретает характер долгосрочного партнерства, и риски и издержки продавца становятся значительно меньше первоначальных, то логичным шагом со стороны покупателя, может стать запрос более выгодных для него коммерческих условий поставки. Продемонстрируем данную ситуацию на рис. 2.

На начальном этапе развития отношений сторон (заштрихованная зона на рис. 2) опасения поставщика (и, как следствие, его суммарные трансакционные издержки) будут достаточно велики. Например, при существенной формализации организатором закупочной процедуры, использовании им специальных мер обеспечения исполнения договора (денежный залог, банковская гарантия), суммарный размер издержек и рисков поставщика вполне способен превышать объем его выручки, поскольку покупатель может вернуть товар или отказаться от дальнейших поставок. Учет этих рисков требует затрат от поставщика (допустим, на оформление страховки), уменьшая его итоговую прибыль.

В то же время, по мере роста параметров сделки, решения спорных вопросов и установления взаимного доверия между сторонами (см. рис. 2, точка $t_{1}$ ) размер суммарных трансакционных издержек становится более приемлемым для поставщика, вследствие чего резонным становится вопрос покупателя о предоставлении ему скидки. При этом размер обсуждаемой скидки может быть оценен потре- бителем расчетным путем, поскольку он сопоставим с теми затратами и рисками, которые уже не несет партнер предприятия. При этом также отметим, что указанная точка выступает точкой перехода заказчика от регламентированных закупок к модели рыночных закупок, т. е. стороны сделки постепенно отходят от «игры с нулевой суммой» ${ }^{2}$ и дальнейшие отношения определяются переговорным путем, исходя из необходимости соблюдения баланса интересов поставщика и потребителя.

Другими словами, ситуация в современном бизнесе такова, что принцип «Я выиграл, а ты проиграл» сменяется принципом «Я выиграл и ты выиграл», т. е. предполагается обоюдное удовлетворение сторон результатами взаимодействия [20, С. 80]. В контексте настоящей статьи играми с нулевой суммой могут считаться закупки типа «издержки плюс», а также регламентированные конкурентные процедуры. Это объясняется тем, что поставщик, поведение которого соответствует модели «издержки плюс», стремится все свои издержки и риски переложить на покупателя, заранее закладывая их в цену товара. Аналогично и потребитель, организующий конкурентные процедуры, ставит перед поставщиком условия, максимально ограничивающие свободу участника закупки (фиксированная цена и сроки поставки, залог участия в процедуре и исполнения договора, оплата по факту и др.). Поэтому в качестве игр с «ненулевой суммой», постепенно переходить к которым и рекомендует автор, могут рассматриваться лишь т. н. рыночные закупки, в рамках которых стороны более склонны к нахождению взаимовыгодных, компромиссных решений.

Также важно отметить, что организатор закупочных процедур в процессе рыночных коммуникаций должен определить «целевую аудиторию» участников для различных видов закупаемой номенклатуры, в рамках которой он сможет обеспечить их эффективное и результативное применение. К примеру, если крупные компании-продавцы в силу масштаба своей деятельности или по иным причинам не желают принимать участие в конкурентных торгах, а производимый ими товар требуется производству, то альтернативой является привлечение к закупочным процедурам их дилеров, которые, как правило, имеют большую организационную гибкость.

В заключение констатируем, что многие проблемы проведения конкурентных закупок, возникающие на микроуровне, могут быть решены на этапе подготовки к проведению процедур. Для этого необходимо оценить обоснованность трансакционных издержек участников, их адекватность при сопоставлении с параметрами планируемой сделки и текущей рыночной ситуацией. Кроме того, поскольку современные взаимоотношения сторон не должны соответствовать модели игры «с нулевой суммой», то для обеспечения результативности проводимых проце-

\footnotetext{
2 Победитель в таких играх получает все выгоды, а проигравший фактически остается ни с чем.
} 
дур покупателю следует стремиться к нахождению точки равновесия с привлекаемыми им участниками. Параллельно промышленному потребителю необходимо осуществлять сбалансированное управление массивом своих контрагентов, формируя на их базе конкурентную среду лояльных поставщиков.

\section{Библиографический список}

1. Боутеллир Р., Корстен Д. Стратегия и организация снабжения. М.: КИА центр, 2006. 128 с.

2. Вагнер Ш.М. Управление поставщиками. М.: КИА центр, 2006. 128 с.

3. Король А.Н., Елисеев А.Е. Основные тенденции в развитии закупочной деятельности // Известия Иркутской государственной экономической академии. 2008. № 2. С. 13-15.

4. Решетник М., Шумаев В. Информационная система предприятия: логистические принципы построения // Конъюнктура товарных рынков. 2005. № 1-2. С. 121-126.

5. Корпоративная логистика: 300 ответов на вопросы профессионалов / Под общ. и науч. ред. д-ра экон. наук, проф. В.И. Сергеева. М.: ИНФРА-М, 2005. 976 c.

6. Модель зрелости закупок. URL: https://home. kpmg.com/ru/ru/home/insights/2011/06/modelof-procurement-maturity.html (дата обращения: 24.03.2017).

7. Грищин А.В. Централизованное снабжение в производственных холдингах. URL: http://www.cfin. ru/management/manufact/centr_supply.shtml (дата обращения: 24.03.2017).

8. Сидорова О.В. Виды и организационные модели электронной коммерции // Креативная экономика. 2012. № 1(61). С. 95-100.

9. Бездушний А. Доверенная третья сторона // Аукционный вестник. 2013. № 133. 15 марта. URL: http://auctionvestnik.ru/pdf/AV_133.pdf (дата обращения: 24.03.2017).
10. Chapman T.L., DempseyJ.J., RamsdellG., ReopelM.R. Purchasing: no time for lone rangers // The McKinsey Quarterly. 1997. N 2. P. 31-40.

11. Денисова А.Л., Уляхин Т.М. Управление конкурентоспособностью промышленного предприятия: аспекты качества. Тамбов: Издательство ТГТУ, 2006. $120 \mathrm{c}$.

12. Шкардун В.Д., Ахтямов Т.М. Методика исследования конкуренции на рынке // Маркетинг в России и за рубежом. 2000. № 4. С. 44-54.

13. Уэбстер Ф. Основы промышленного маркетинга. М.: Издательский Дом Гребенникова, 2005. $416 \mathrm{c}$.

14. Чалабян А. Снабженческая революция // Вестник McKinsey. 2003. № 2(4). С. 133-148.

15. Антоненко E.B. Управление трансакционными издержками оппортунизма на промышленном предприятии при покупке и реализации товаров // Вестник ЮУрГУ. Сер. «Экономика и менеджмент». 2016. T. 10. № 4. C. 12-17. DOI: $10.14529 / \mathrm{em} 160402$

16. ФАС предупредила «Русал» и ММК о злоупотреблении доминирующим положением на рынке. URL: http://kommersant.ru/doc/3182982 (дата обращения: 24.03.2017).

17. При поддержке ФАС России «Роснефть» и «Саянскхимпласт» заключили мировое соглашение. URL: http://fas.gov.ru/press-center/news/detail. html?id=48665 (дата обращения: 24.03.2017).

18. Король А.Н. Конкурентные закупки и рыночные коммуникации промышленного предприятия // Власть и управление на Востоке России. 2008. № 2. C. 29-33.

19. Король А.Н. Методология управления рыночными коммуникациями в закупочной деятельности промышленного предприятия. Автореф. дис. ... д-ра. экон. наук. Хабаровск, 2009. 40 с.

20. Карнаухов С. Логистика как управленческая теория и система управления материальным потоком // РИСК: ресурсы, информация, снабжение, конкуренция. 2006. № 2. С. 79-90.

Ekonomika $v$ promyshlennosti $=$ Economy in the industry

2017, vol. 10, no. 1, pp. 53-58

ISSN 2072-1633 (print)

ISSN 2413-662X (online)

\section{Organization of interaction between industrial consumers and suppliers within the framework of procurement procedures: problems and solutions at the micro level}

V.I. Pleshchenko - v_pl@mail.ru

JSK «Goznak», 3«V 》 Petropavlovskaya Krepost, SanktPeterburg 197046, Russia

Abstract. The article discusses various approaches to procurement of products for production needs, analyzes their advantages and disadvantages. It is shown that, in spite of expanding the practice of purchasing goods from the single source for modern industrial enterprises typical for Western countries in Russia approaches to alternative suppliers, competition of various bids of participants of procurement procedures are still preferable. When analyzing the problems at the micro level, a special importance of the stage of preparation for the purchases on which to assess the reasonableness of the transaction costs of the participants, their adequacy in relation to the parameters of the proposed transaction and current market conditions is paid. Since modern relationship of parties must not match a "zero-sum game" model, to ensure the efficiency of procedures the buyer should find a point of balance with participants. The 
author believes that procurement model which is popular today could be efficient mostly on short distances. Expansion of the bidders can increase the result, but in this case the organizer faces new risks and challenges. Therefore, in the long term as a more rational option for industrial companies appears the structuring relations with suppliers to use models of market purchases of materials of industrial purpose, more suitable for the development of partnerships. Industrial consumer needs to implement a balanced regulation of contractors crowd with forming a competitive environment of loyal suppliers.

Keywords: procurement procedure, single source, competitive procurement, transaction costs, the price of loyalty, long-term cooperation

\section{References}

1. Boutellir R., Korsten D. Strategiya i organizatciya snabjeniya [Strategy and organization of supply]. Moscow: KIA tcentr, 2006. 128 p. (In Russ.)

2. Wagner, St.M. Upravlenie postavschikami [Vendor management]. Moscow: KIA tcentr, 2006. 128 p. (In Russ.)

3. Korol A.N., Eliseev A.E. Main tendencies for the development of purchasing activity. Izvestiya Irkutskoi gosudarstvennoi ekonomicheskoi akademii. 2008. No. 2. Pp. 13-15. (In Russ.)

4. Reshetnik M., Shumaev V. Informatcionnaya sistema predpriyatiya: logisticheskie printcipy postroeniya. Kon'yunktura tovarnykh rynkov. 2005. No. 1-2. Pp. 121-126. (In Russ.)

5. Corporativnaya logistika: 300 otvetov na voprosy professionalov [Corporate logistics: 300 answers to questions of professionals]. Moscow: INFRA-M, 2005. 976 p. (In Russ.)

6. Model' zrelosti zakupok [Maturity model of purchases]. Available at: https://home.kpmg.com/ru/ru/home/ insights/2011/06/model-of-procurement-maturity.html (accessed: 24.03.2017). (In Russ.)

7. Grishin A.V. Tcentralizovannoe snabjenie v proizvodstvennykh holdingakh [Centralized supply in production holdings]. Available at: http://www.cfin.ru/management/ manufact/centr_supply.shtml (accessed: 24.03.2017). (In Russ.)

8. Sidorova O.V. Types and Organization Models of Electronic Commerce in Modern Economy. Kreativnaya ekonomika $=$ Creative Economy. 2012. No. 1(61). P. 95-100. (In Russ.)
9. Bezdushnii A. Doverennaya tret'ya storona [Trusted third party]. Auktcionnyi vestnik. 2013. No. 133. 15 March. Available at: http://auctionvestnik.ru/pdf/ AV_133.pdf (accessed: 24.03.2017) (In Russ.)

10. Chapman T.L., Dempsey J.J., Ramsdell G., Reopel M.R. Purchasing: no time for lone rangers. The McKinsey Quarterly. 1997. No. 2. Pp. 31-40.

11. Denisova A.L., Ulyakhin T.M. Upravlenie konkurentosposobnost'yu promyshlennogo predpriyatiya: aspekty kachestva [Management of competitiveness of the industrial enterprise: aspects of quality]. Tambov: Publishing House TGTU, 2006. 120 p. (In Russ.)

12. Shkardun V.D., Akhtyamov T.M. Technique of research of competition in the market. Marketing $v$ Rossii $i$ za rubezhom. 2000. No. 4. P. 44-54. (In Russ.)

13. Webster F. Osnovy promyshlennogo marketinga [Bases of industrial marketing]. Moscow: Grebennikov Publishing House, 2005. 416 p. (In Russ.)

14. Chalabyan A. The supply revolution. Vestnik McKinsey. 2003. No. 2(4). Pp. 133-148. (In Russ.)

15. Antonenko E.V. Management of the opportunistic behavior costs as a component of industrial company transaction costs in the process of buying and selling of goods. Bulletin of the South Ural State University. Ser.: Economics and management. 2016. Vol. 10. No. 4. Pp. 12-17. (In Russ.). DOI: 10.14529/em160402

16. FAS predupredila «Rusal» I MMK o zloupotreblenii dominiruyuschim polozheniem na rynke. Available at: http://kommersant.ru/doc/3182982 (accessed: 24.03.2017). (In Russ.)

17. Pri podderzhke FAS Rossii «Rosneft» $i$ «Sayanskkhimplast» zaklyuchili mirovoe soglashenie. Available at: http://fas.gov.ru/press-center/news/detail. html?id=48665 (accessed: 24.03.2017). (In Russ.)

18. Korol A.N. Competitive purchases and market communications of an industrial enterprise. Vlast' $i$ upravlenie na Vostoke Rossii. 2008. No. 2. Pp. 29-33. (In Russ.)

19. Korol' A.N. Metodologiya upravleniya rynochnymi kommunikatciyami $v$ zakupochnoi deyatel'nosti promyshlennogo predpriyatiya [Methodology of management of market communications in purchasing activity of the industrial enterprise]. Avtoref. dis. ... d-ra. ekon. nauk. Khabarovsk, 2009. 40 p. (In Russ.)

20. Karnaukhov S. Logistics as a management theory and material flow management system. RISK: resursy, informatciya, snabjenie, knkurentciya. 2006. No. 2. Pp. 79-90. (In Russ.)

Information about author: Cand. Sci. (Econ.), Head of Equipment \& Materials Purchasing Department. 